\title{
O Tratamento de Desintoxicação ao Dependente Químico de Drogas Ilícitas Sob um Prisma Constitucional
}

\author{
THE DETOX TREATMENT FOR CHEMICAL DEPENDENCE OF ILLICIT \\ DRUGS ON A CONSTITUTIONALAPPROACH
}

Tiago Toniêto ${ }^{(*)}$

\section{RESUMO}

A saúde está positivada no ordenamento jurídico pátrio como um direito e uma garantia fundamental do indivíduo. Nesse contexto, este trabalho analisa o conteúdo das regras e princípios, que emanam do referido ordenamento, com vistas à concessão de tratamento de desintoxicação ao dependente químico de substância ilícita. Para tanto, indispensável demonstrar que a toxicomania é reconhecida como uma doença pela Organização Mundial da Saúde.

\section{Palavras-chave} Saúde.

Dignidade; Direito Fundamental; Drogas Ilícitas; Entes Federativos;

\section{ABSTRACT}

Health is positely valued in the vernacular as an individual right and fundamental guarantee. In this context, this work analyzes the rules and principles that issue from this legal system referring to the provision of detoxification treatment to chemical dependent of illicit substance. Thus, it is essential to show that drug addiction is recognized as a disease by the World Health Organization.

(*) Advogado, aluno do curso de especialização em Direito Tributário da Rede de Ensino Luiz Flávio Gomes. E-mail: <tiagotonieto @ hotmail.com>. Recebido em 25.2.09. Revisado em 27.5.09. Aprovado em 15.6.09. 


\section{Keywords}

Dignity; Fundamental Right; Federal Entities; Health; Illicit Drugs.

\section{INTRODUÇÃO}

Objetiva-se no texto deste trabalho, demonstrar as leis que fazem menção sobre os serviços e ações que devem ser instituídos pelos órgãos públicos e privados, em prol da saúde do dependente químico de drogas ilícitas.

Para tanto, ter-se-á como embasamento normativo-dimensional, o dever do Estado no que tange à promoção de ações que visem a prevenir e a recuperar a saúde do indivíduo. Isso porque ela se encontra inserida no contexto basilar de um princípio que fundamenta a República Federativa do Brasil, intitulado Dignidade da Pessoa Humana.

Assim, sem intuito de esgotar a bibliografia e divergências existentes sobre o tema, busca-se compreender a inter-relação de circunstâncias que perfazem o sentido jurídico do termo dignidade, que deve ser proporcionada ao toxicômano, bem como, a abrangência do seu conceito para a doutrina brasileira.

Em suma, torna-se mister fazer um relato circunstanciado da saúde como um direito e garantia fundamental no ordenamento jurídico pátrio.

Por sua vez, o indivíduo que atua na compra e venda do tráfico de drogas termina por consumir as substâncias ilícitas, as quais são o objeto de comercialização. Dependendo da freqüência e da quantidade de uso dessas substâncias químicas, elas podem acarretar danos ao organismo da pessoa, a ponto de gerar-lhe dependência. Essencial, então, determinar se a toxicomania é reconhecida como uma doença.

Importa ainda, tecer uma análise dos textos constitucionais dos Estados que compõem a Federação Brasileira no que tange à proteção da saúde do dependente de substância ilícita, em face da autonomia legislativa outorgada a esses entes pela Constituição Federal de 1988. Por fim, pretende-se expor a organização do Sistema Único de Saúde (SUS) e suas diretrizes relevantes, estabelecidas pela Constituição Federal de 1988, no que consiste ao atendimento da população por meio de serviços que visem a erradicar doenças e amenizar sofrimentos com técnicas de preveni-las.

\section{A SAÚDE COMO DIREITO FUNDAMENTAL}

A organização do Estado brasileiro demonstra que o essencial para a qualidade de vida de um povo, é que os direitos sociais previstos na Consti- 
tuição Federal de 1988 sejam oportunizados. Isso porque denotam uma concepção fundada na idéia de sobrevivência racional e atuam como meios para que as pessoas possam alcançar a dignidade humana, enquanto seres dotados de vida.

Nessa seara, a vigente Constituição trouxe inovações no ordenamento jurídico, ao positivar, de forma expressa, que são de responsabilidade do Estado a garantia, a proteção e a efetividade da saúde aos brasileiros e aos estrangeiros residentes ou não residentes que se encontram no país. ${ }^{(1)}$ Além disso, na sua organização textual, inseriu esse bem indispensável para o ciclo de duração de uma vida, em seu Título II, cuja denominação completa a sua importância: dos direitos e garantias fundamentais.

Assim, a saúde como um direito fundamental do cidadão decorre de um processo histórico, que ganha importância e positivação em documentos jurídicos na esfera internacional de forma expressa, ou, implícita e indiretamente por meio do Princípio da Dignidade da Pessoa Humana, tendo em vista que o respeito a esse princípio depende também de mecanismos para prevenir e erradicar doenças quando se manifestam. Desse modo, a promoção pelo direito à saúde encontra-se prevista na Constituição da Organização Mundial da Saúde de 1946, na Declaração Universal dos Direitos do Homem de $1948^{(2)}$ e no Pacto Internacional de Direitos Econômicos Sociais e Culturais de $1976^{(3)}$, sendo o país do Brasil um dos seus signatários.

Como visto, os termos utilizados para intitular tais documentos são diversos, mas o essencial é que vigem direcionados a proteger a integridade humana e reconhecem direitos a serem invocados na esfera internacional. Adotando o posicionamento de Cury, "numa visão lata, não há diferenças entre as expressões direitos do homem, direitos humanos e direitos fundamentais." Entretanto, em sentido estrito, esses enunciados são usados da seguinte forma:

(1) Importante reflexão faz SARLET, Ingo Wolfgang. Algumas considerações em torno do conteúdo, eficácia e efetividade do direito à saúde na Constituição de 1988. Interesse Público. Porto Alegre: Notadez, n. 12, p. 96, out./dez. 2001, no que diz respeito à proteção da saúde dos estrangeiros não residentes no Brasil. Menciona que o artigo 5ㅇ, caput, da vigente Constituição Federal não pode ser interpretado literalmente, salvo melhor juízo, pois caso contrário um infeliz turista (ao menos quando acometido de alguma enfermidade) que esteja gozando de suas férias no Brasil, poderia - com base nesse entendimento - ser barrado na entrada de qualquer hospital (mesmo da rede pública), sob o argumento de não the ser assegurado o direito à saúde, não podendo até mesmo recorrer ao Judiciário para reclamar o seu atendimento de forma compulsória.

(2) Menciona o preâmbulo da referida declaração: "Considerando que, na Carta, os povos das Nações Unidas proclamam, de novo, a sua fé nos direitos fundamentais do homem, na dignidade e no valor da pessoa humana, na igualdade de direitos dos homens e das mulheres e se declaram resolvidos a favorecer o progresso social e a instaurar melhores condições de vida dentro de uma liberdade mais ampla [...]" Mas é em seu artigo 25 que o direito à saúde ganha destaque: "1. Toda a pessoa tem direito a um nível de vida suficiente para lhe assegurar e à sua família a saúde e o bem-estar, principalmente quanto à alimentação, ao vestuário, ao alojamento, à assistência médica e ainda quanto aos serviços sociais necessários, e tem direito à segurança no desemprego, na doença, na invalidez, na viuvez, na velhice ou noutros casos de perda de meios de subsistência por circunstâncias independentes de sua vontade. [...]."SEITENFUS, Ricardo (Org.). Legislação internacional. São Paulo: Manole, 2004. p. 250 e 253. 
Direitos do homem - expressão mais utilizada na doutrina jusnaturalista contratualista dos séculos XVII a XIX (Locke, Hobbes, Rousseau e Kant). Diz respeito ao direito natural e aos direitos de liberdade dele decorrentes; Direitos Humanos - expressão utilizada em relação aos direitos e liberdades previstos em tratados internacionais. É um termo internacionalista dos direitos fundamentais. Direitos fundamentais [...] podem ser conceituados como o conjunto de normas que cuidam dos direitos e liberdades garantidos institucionalmente pelo direito positivo de determinado Estado; devem sua denominação ao caráter básico e fundamentador de toda ordem jurídica, com limitação espacial e temporal. ${ }^{(4)}$

Nesse ínterim, cumpre destacar, que vinculado ao conceito das expressões acima transcritas, está um princípio que fundamenta a República Federativa do Brasil: o da Dignidade da Pessoa Humana. Previsto no art. 1ํㅡㄴ inciso III, da CF/1988, reforça o papel do Estado na promoção, recuperação e prevenção da saúde do dependente químico de drogas ilícitas. Sendo a saúde condição indispensável à subsistência da espécie humana, não há como negar a interconexão existente dos fatos e das circunstâncias que exigem a sua promoção com os atributos caracterizadores do referido princípio.

Assim, antes de uma edificação doutrinária de sua titulação, é indispensável entender o significado do termo princípio, a fim de auxiliar a sua compreensão integral no constitucionalismo pátrio, não pretendendo investigar as suas diversas oscilações contextuais.

Para isso, segue-se o caminho de Karl Larenz que define os princípios como normas de imensa relevância "para o ordenamento jurídico, na medida em que estabelecem fundamentos normativos para a interpretação e aplicação do direito, deles decorrendo, direta ou indiretamente, normas de comportamento."(5) Consistem em mandamentos diretivos para solucionar uma relação jurídica existente ou possível, para a qual não há dispositivos de lei regulamentando-a de forma direta. Mesmo dotados de significativo grau de abstração, tais mandamentos são indispensáveis para o respeito e garantia material dos direitos fundamentais à população.

(3) O preâmbulo do presente pacto consagra que os direitos nele contidos decorrem da dignidade inerente à pessoa humana, consagrando em seu artigo 12 que "1. Os Estados partes no presente pacto reconhecem o direito de todas as pessoas de gozar do melhor estado de saúde física e mental possível de atingir. 2. As medidas que os Estados partes no presente pacto tomarem com vista a assegurar o pleno exercício deste direito deverão compreender as medidas necessárias para assegurar: [...] d. A criação de condições próprias a assegurar a todas as pessoas serviços médicos e ajuda médica em caso de doença." SEITENFUS, Ricardo (Org.). op. cit., p. 292 e 296.

(4) CURY, leda Tatiana. Direito fundamental a saúde: evolução normatização e efetividade. Rio de Janeiro: Lumem Júris, 2005. p. 1.

(5) LARENZ, Karl apud ÀVILA, Humberto. Teoria dos princípios da definição à aplicação dos princípios jurídicos. 4. ed. São Paulo: Malheiros Ed., 2005. p. 27. 
Uma proposta de conceito ao Princípio da Dignidade da Pessoa Humana foi formulada por Sarlet, que por sua vez, tomado por uma atitude da ousadia, como ele próprio reconhece, entende ser

a qualidade intrínseca e distintiva de cada ser humano que o faz merecedor do mesmo respeito e consideração por parte do Estado e da comunidade, implicando, neste sentido, um complexo de direitos e deveres fundamentais que assegurem a pessoa tanto contra todo e qualquer ato de cunho degradante e desumano, como venham a Ihe garantir as condições existenciais mínimas para uma vida saudável, além de propiciar e promover sua participação ativa e co-responsável nos destinos da própria existência e da vida em comunhão com os demais seres humanos. ${ }^{(6)}$

Denota-se do conceito supracitado, que condições mínimas para a existência de uma vida racional devem ser asseguradas pelo Estado, lembrando que esse órgão deve atuar de forma positiva para cumprir com essa obrigação, ou seja, implementando, efetivando, concretizando, os direitos e as garantias fundamentais. Saliente-se que somente haverá valorização ao Princípio da Dignidade Humana quando ao indivíduo, portador de alguma enfermidade, forem oportunizados meios de curá-la com atendimento especializado e tratamento adequado.

Contudo, cumpre demonstrar que as substâncias ilícitas, quando em contato com o organismo humano sem acompanhamento de profissional formado em medicina ou realizado com grande freqüência, e de modo excessivo, geram dependência. Esta, por sua vez, deve ser tratada como uma doença, estando o dependente químico sob a proteção da legislação sanitária.

\section{A DEFINIÇÃO DE DEPENDÊNCIA QUÍMICA}

Explica Velo, utilizando-se dos ensinamentos de Delmanto, que a Organização Mundial da Saúde expôs em termos claros e precisos, ao elaborar a lista de Classificação Internacional de Doenças (CID-10) publicada periodicamente há mais de um século e atualmente, em sua Décima Revisão, que "dependência" é "um estado psíquico e algumas vezes físico" provindo "de uma interação entre um organismo vivo e uma droga," que se caracteriza por uma conduta e outros fatores que, inúmeras vezes, "inclui a compulsão a tomar a droga, contínua ou periodicamente", com o propósito de experimentar seus efeitos psicológicos e, em alguns casos,

(6) SARLET, Ingo Wolfgang. Dignidade da pessoa humana e direitos fundamentais na Constituição Federal de 1988. Porto Alegre: Livr. do Advogado, 2001. p. 60. 
"evitar o desconforto de sua ausência." (7) Classificação Internacional de Doenças "publicada periodicamente há mais de um século e atualmente, em sua Décima Revisão (CID-10).

A dependência então, consoante a OMS, é caracterizada pela alteração mental e corpórea do indivíduo em decorrência do uso de drogas. Concorre, para isso, a influência de fatores como a curiosidade em sentir os efeitos das drogas e a necessidade de tê-las no organismo, sabendo que o prazer e a coragem para enfrentar os problemas sociais ${ }^{(8)}$ são acompanhados de curtos momentos de alegria.

Em razão de que a constituinte delegou poderes de auto-organização aos Estados, podendo inclusive editar suas próprias constituições desde que não violem normas federais e não fujam do âmbito de suas competências, a seguir, será analisada a preocupação que o legislador Estadual teve em proteger o dependente químico de drogas ilícitas.

\section{CONSTITUIÇÕES ESTADUAIS E A PROTEÇÃO AO DEPENDE QUIMMICO DE DROGAS ILÍCITAS}

Prevê o art. 23, inciso II, da Carta Magna de 1988, ser competência comum da União, dos Estados, do Distrito Federal e dos Municípios, cuidarem da saúde e promoverem a assistência pública a todos, inclusive aos portadores de algum tipo de deficiência. Explica Dallari, utilizando-se das palavras de Silva, que a competência comum ocorre quando não existe primazia entre os responsáveis pela execução do encargo. De maneira inversa, supõe-se a igualdade das distintas esferas da federação que devem atuar conjuntamente, "sem que o exercício de uma venha a excluir a competência da outra."(9) Ambas esferas administrativas deverão cumprir com sua função que Ihes fora outorgada para que a saúde seja concretizada tanto no seu aspecto preventivo quanto no curativo.

Dispõe também o art. 24, inciso XII, da Lei Fundamental, uma competência concorrente entre a União, os Estados e o Distrito Federal, para criarem suas próprias leis visando à proteção e defesa da saúde. Isso significa que se inicia

(7) VELO, Joe Tennyson. Uso de substâncias psicoativas: aspectos criminológicos e políticos. Revista Brasileira de Ciências Criminais, n. 18, p. 109-122, abr./jun. 1997.

(8) Não pretendendo esgotar a lista de problemas sociais que comprometem a qualidade de vida na população em tempos atuais, citam-se alguns como: a falta de empregos, a carência de um sistema educacional que oportunize a todos acesso ao conhecimento, a falta de moradias com água potável e energia elétrica, a ausência de atendimento na área da saúde por profissionais qualificados às pessoas que não possuem condições de acesso aos bens que possam amenizar esses problemas por meio particular.

(9) SILVA, J. A. apud DALLARI, Sueli Gandolfi. Os Estados brasileiros e o direito à saúde. São Paulo: Hucitec, 1995. p. 38. 
a execução comum das tarefas políticas por um critério que, além de supor o acordo, ou a vontade recíproca do trabalho conjunto, estabelece a prioridade para determinar a disciplina no exercício daquela atividade. É a chamada competência concorrente. Sua caracterização depende, portanto, da existência de uma única tarefa, que será desempenhada por mais de uma unidade federativa, segundo um critério de primazia anteriormente definido. ${ }^{(10)}$

Em razão da autonomia concedida aos Estados, principalmente atendendo à determinação do art. 11 ${ }^{(11)}$ dos Atos das Disposições Constitucionais Transitórias, esses criaram um conjunto de regras e princípios para sua organização local, e promulgaram suas próprias constituições, reafirmando suas obrigações de programarem políticas públicas que visem à erradicação de doenças e ao fornecimento de condições para curá-las quando atingem o organismo humano.

Não são muitas as Constituições dos Estados brasileiros que prevêem a obrigação do ente público em zelar pela saúde do dependente químico de substância ilícita. Para ser mais específico, existem apenas três que se enquadram na delimitação do tema a que se propôs escrever: a de Sergipe, a do Estado do Rio Grande do Sul e a de São Paulo. Todavia, as demais Constituições Estaduais não podem deixar de prestarem assistência a todos os cidadãos que possuírem essa doença, tendo em vista que, onde houver enfermidades, o Princípio da Dignidade da Pessoa Humana está sendo violado e cabe ao Estado intervir para que isso não ocorra.

A Constituição do Estado do Sergipe estabelece, em seu art. 193, inciso $X X I$, que cabe ao Estado garantir os mecanismos da rede pública de serviços de saúde, ordenada sob a forma de um Sistema Único de Saúde, descentralizado em distritos sanitários, tendo como meta o "desenvolvimento de programas específicos de prevenção e atendimento ao dependente de entorpecentes e drogas afins."

Oportuno tecer breve comentário sobre a formação de distritos sanitários no Estado de Sergipe consoante previsão no texto da sua Carta Política. Tendo em vista a faculdade de os Estados delegarem aos Municípios a promoção de serviços relacionados à saúde, bem como a do poder público em contratar empresas privadas para o fornecimento dos mesmos, objetivase, com a construção desses institutos, redirecionar e mudar a forma de organização e a essência "das ações e serviços de saúde, de modo a responder às demandas da população," satisfazer as necessidades no que

(10) DALLARI, Sueli Gandolfi. op. cit., p. 38.

(11) Art. 11. Cada Assembléia Legislativa, com poderes constituintes, elaborará a Constituição do Estado, no prazo de um ano, contado da promulgação da Constituição Federal, obedecendo-se aos princípios desta.

Parágrafo único. Promulgada a Constituição do Estado, caberá à Câmara Municipal, no prazo de seis meses, votar a Lei Orgânica respectiva, em dois turnos de discussão e votação, respeitado o disposto na Constituição Federal e na Constituição Estadual. 
se refere à cura e erradicação de doenças "e, fundamentalmente, contribuir para a solução dos problemas de saúde da população que vive e trabalha no espaço territorial e social do Distrito Sanitário."(12)

A Constituição gaúcha, por sua vez, reconhecendo os efeitos nocivos que o uso de entorpecentes causa no organismo do ser humano não omitiu a responsabilidade do órgão público em prover assistência por meio de políticas públicas que visem a prevenir e a recuperar a saúde do cidadão que teve contato com algum tipo de droga ilícita, e por tal motivo necessita de ajuda. Em seu art. 193, ${ }^{(13)}$ expressa a implementação de um órgão colegiado com orçamento próprio, definido em lei, encarregado de elaborar técnicas educacionais para o não-uso de drogas, o que vai proporcionar um contato pessoal com aqueles que já se enquadram em alguma das categorias elaborada pela Organização Mundial da Saúde, com relação à freqüência de uso de substâncias ilícitas.

Já o legislador constituinte do Estado de São Paulo atribui ao ente público o dever de garantir aos usuários de substâncias que geram dependência física ou psíquica, o funcionamento de unidades terapêuticas. ${ }^{(14)}$ Eis o ponto fundamental para que o indivíduo possa desenvolver atividades que visem à sua ressocialização, mediante o auxílio de profissionais que controlem o horário e a certeza de que a medicação adequada para a desintoxicação do organismo está sendo ingerida, pois a primeira reação do toxicômano é não querer utilizar as medicações no horário adequado, principalmente, na fase da abstinência, quando ele necessita da droga para se sentir bem.

Nesse contexto, a proteção do direito à saúde também está positivada na Lei n. 8.080/90 que forma o todo do sistema sanitário estadual, regulamenta o campo de atuação do SUS, procurando demonstrar o direito à saúde como um processo de descentralização.

\section{O SISTEMA ÚNICO DE SAÚDE NA LEGISLAÇÃO BRASILEIRA}

A carência em tornar efetivo o direito à saúde à população brasileira, em alguns casos, ou até mesmo a demora em fornecê-la, não advém da falta

(12) MENDES, Eugênio Vilaça et. al. Distritos sanitários: conceitos-chave. In: (Org.). Distrito Sanitário: o processo social de mudança das práticas sanitárias do sistema único de saúde. 4. ed. São Paulo - Rio de Janeiro: Hucitec - Abrasco, 1999. p. 162.

(13) É o texto do referido artigo: "O órgão colegiado estadual encarregado da política de entorpecentes, com estrutura, composição e dotação orçamentária definidas em lei, terá a atribuição primordial de formular as diretrizes dessa política no âmbito do Estado, objetivando a educação preventiva contra o uso de substâncias entorpecentes ou que determinem dependência física ou psíquica, e a assistência e recuperação dos dependentes."

(14) Vide artigos 223, inciso II, alínea d; e 230, respectivamente do texto da Constituição referida. 
de um ordenamento jurídico sem consistência de conteúdo que consinta nessa realidade, e deixe de reconhecer que a concretização desse bem essencial à Dignidade Humana é uma obrigação do poder público.

A bem da verdade existe uma demanda muito grande para ser atendida e, de certa forma, procedimentos burocráticos (mas que não comprometam gravames ao doente no que tange à prevenção e à recuperação de sua saúde) devem ser instituídos, até mesmo por meio de legislação, para que o serviço seja encarado com seriedade por ambas as partes: administrador e administrados.

No Brasil, responsabilizaram-se todos os entes que compõem a federação, com o encargo de que é essencial maior eficiência por parte do poder público na prestação do direito à saúde à população. Nesse contexto, vige no referido país um Sistema Único de Saúde, ${ }^{(15)}$ organizado por meio de ações e de serviços de caráter público, possuindo como característica principal a descentralização, pela qual o "SUS remete a execução das ações e serviços públicos de saúde para os entes locais, que, próximos da população, possuem a melhor condição de avaliar as necessidades mais prementes e desenvolver as condutas mais eficazes de prevenção e tratamento. ${ }^{(16)}$

O sistema de saúde brasileiro está regulamentado pela Lei n. 8.080 de 19 de setembro de 1990 e reconhece, em seu art. $2^{\circ}$, caput, que a saúde é um direto fundamental do ser humano, destacando caber ao Estado implementar as condições indispensáveis ao seu inteiro exercício. Compõe-se de um conjunto de ações e serviços de saúde, fornecidos por órgãos e instituições de caráter público em âmbito federal, estadual e municipal, da administração direta e indireta e das fundações mantidas pelo Poder Público, consoante art. $4^{\circ}$, caput, desta Lei.

Com relação aos princípios e diretrizes que regulamentam o SUS, previstos no art. $7^{\circ}$ e seus incisos da Lei $n$. 8.080/90, instituídos em conformidade com o disposto no art. 198 da atual Constituição brasileira, dois deles merecem ser trabalhados pela importância que possuem na ordem jurídica e na relação com a problemática do tema: o da universalidade e da igualdade.

O primeiro se refere que as ações e os serviços públicos exercidos pelo SUS devem visar a alcançar todo e qualquer cidadão, independentemente de condições financeiras, raça, cor sexo, ou qualquer outro atributo. Esses serviços se encontram em conexão com a classificação subjetiva do direito à saúde. Nas palavras de Weichert, as ações tanto no aspecto de prevenir quanto no de curar, "devem ser concebidas como de livre acesso e desenvolvidas para toda a população, salvo, obviamente, quando destinadas, a um determinado grupo social em função de patologias específicas." (17)

(15) Há quem entenda, de forma contrária. Para CURY, leda Tatiana. op. cit., p. 93, o Brasil possui um sistema misto de saúde, ou seja, público e privado.

(16) WEICHERT, Marion Alberto. Saúde e federação na Constituição Brasileira. Rio de Janeiro: Lumen Juris, 2004. p. 166.

(17) Id. Ibid., p. 158. 
Em consonância com o princípio anteriormente comentado, encontra-se o princípio da igualdade, ou seja, o que foi proporcionado para um, deve ser ao mesmo tempo concedido ao outro; não pode haver escolhas pelo sistema uma vez que referido procedimento seria trágico, pois se estaria sacrificando o direito de um em benefício do outro, o que acarretaria violação ao princípio em questão, inserido no rol dos direitos e garantias fundamentais.

O contexto sócio-jurídico do princípio da universalidade e da igualdade faz com que um ponto fundamental deva ser observado pelo Poder Judiciário, quando o mesmo for acionado pelo toxicômano na busca de um tratamento de desintoxicação em estabelecimento adequado. Trata-se do fato de que o Judiciário deve conhecer a realidade local antes de instituir judicialmente o atendimento postulado, pois não havendo leitos em hospitais ou vagas em clínicas, pode burlar uma lista de espera. Logo estaria sendo propulsor da singularidade e da desigualdade.

Outro ponto que deve ser destacado, e de considerado apreço na promoção e recuperação da saúde da população, é a regra explícita no art. $43^{(18)}$ da Lei do SUS, que prevê a gratuidade das ações e dos serviços de saúde, contraídos com o poder público, ou melhor, quando forem prestados por ele. No entendimento de Weichert, inexiste extensão ideal na estrutura do Estado social brasileiro para cobrar donativos pelos serviços estatais na área sanitária, propiciados à população, em razão dos seguintes motivos:

Primeiro, pelo próprio conteúdo da universalidade, que conduz ao dever do Estado de cuidar da saúde de todos os cidadãos indistintamente [...]. A cobrança implicaria, assim, em novamente se restringir os serviços a determinada parcela da população (aquela que tem condições de contribuir) e, com isso, afastar-seia a universalidade. Vale dizer, os conceitos de universalidade e onerosidade são auto-excludentes. [...] Segundo, pela atuação estatal de promoção da saúde ser um serviço público genérico e indivisível, incompatível com a cobrança de taxas (art. 145, inciso II, da Constituição) e, muito menos, de preço público (pois essa espécie de cobrança traz subjacente o conceito de serviço estatal prestado com fins de lucro e com natureza contraprestacional). [...] Terceiro, pela condição social da população brasileira, esmagada pela pobreza (basta examinar os níveis de distribuição de renda), que reduziria a possibilidade de cobrança - sem supressão das condições mínimas de sobrevivência - a um percentual mínimo do povo. ${ }^{(19)}$

(18) Art. 43. A gratuidade das ações e serviços de saúde fica preservada nos serviços públicos contratados, ressalvando-se as cláusulas dos contratos ou convênios estabelecidos com as entidades privadas.

(19) WEICHERT, Marion Alberto. op. cit., p. 161-163. Apesar dessas afirmações focaliza esse mesmo autor, que a universalidade em obter acesso às ações de saúde não vedam o Poder Público de obter ressarcimento dos dispêndios financeiros que incorre com o atendimento de pessoas que, por livre e espontânea vontade, ou por conseqüência de contrato de trabalho, possuem segurosaúde ou contrato de assistência médica com empresa privada. 
Depreende-se do texto constitucional que as empresas privadas possuem a liberdade de desenvolver institutos com a finalidade de prestar assistência sanitária à população. Prevê também, a possibilidade de o sistema particular auxiliar, de modo complementar, o SUS mediante a elaboração de contrato público, atendendo às diretrizes e aos objetivos previstos naquele, dando preferência às entidades filantrópicas e às sem fins lucrativos. Por sua vez, não poderá o poder público destinar auxílios financeiros para as entidades privadas que visam a fins lucrativos. ${ }^{(20)}$

Por sua vez, a direção do SUS é exercida de forma uníssona em cada esfera de governo, sendo comandada no âmbito da União, pelo Ministério da Saúde; e, dos Estados, do Distrito Federal e dos Municípios pela respectiva Secretaria de Saúde ou órgão equivalente.(21)

Tendo o Município adquirido poder para executar as políticas públicas que instituir mediante suas fontes de arrecadação, as quais se consubstanciam na cobrança de impostos, ${ }^{(22)}$ e poder de legislar sobre matérias de interesse local, inclusive sanitárias, o art. 17, inciso I da lei do SUS prevê a possibilidade de a Direção Estadual do sistema delegar, a cargo do ente público municipal, a concretização dos serviços e das ações de saúde, que "caso o Estado decida pela sua municipalização" como ocorreu no "Estado do Rio Grande do Sul (art. 241, caput, da Constituição gaúcha), não poderá mais decidir sobre o planejamento do Sistema, bem como passará a colaborar técnica e financeiramente com os Municípios."(23)

Méritos são devidos ao legislador constituinte gaúcho, uma vez que, agindo de tal maneira, valorizou o ente público local e, ao mesmo tempo, responsabilizou os prefeitos e sua equipe administrativa pela promoção da saúde.

Leva-se em consideração que os prefeitos possuem maior facilidade em se deslocarem até os postos de saúde e hospitais e, por meio dessa ação, estabelecerem um diálogo com os agentes que atuam na área da saúde para saber que ponto deve ser priorizado pelas políticas públicas na erradicação e na prevenção de doenças. Por outro lado, lembra-se que esse diálogo deve se estender com os demais integrantes da sociedade, para os quais se devem dirigir todas as ações que praticar enquanto administrador de um órgão público.

(20) Vide art. 199, caput, §§ $1^{\circ}$ e $2^{\circ}$ da CF/1988.

(21) É o conteúdo do artigo 9o, caput, incisos I, II, III da Lei 8.080/90.

(22) Art. 156. Compete aos Municípios instituir impostos sobre:

I - propriedade predial e territorial urbana;

II - transmissão inter vivos, a qualquer título, por ato oneroso, de bens imóveis, por natureza ou acessão física, e de direitos reais sobe imóveis, exceto os de garantia, bem como cessão de direitos a sua aquisição;

III - serviços de qualquer natureza, não compreendidos no art. 155, II, definidos em lei complementar; [...].

(23) SCHWARTZ, Germano André Doederlein. Direito à saúde: efetivação em uma perspectiva sistêmica. Porto Alegre: Livr. do Advogado, 2001. p. 104. 
Entretanto, menciona Schwartz, "a adesão não é automática. Para que faça parte do sistema, o Município deve-se credenciar perante o SUS, obedecendo aos procedimentos técnicos existentes a respeito. Sua contrapartida financeira corresponderá a, no mínimo, 15\% (quinze por cento) do orçamento público municipal, que será depositado no Fundo Municipal de Saúde, administrado pelo Conselho Municipal da Saúde."(24)

Ponto importante a ser trabalhado é a forma de financiamento do SUS. A sociedade é um dos órgãos que deve contribuir de forma direta e indireta. Os entes que formam a República Federativa do Brasil devem destinar parte de suas arrecadações tributárias a essa finalidade, de forma regular e automática. Evitando-se técnicas burocráticas desnecessárias, lembram Ivan de Carvalho e Lenir Santos que,

Como entre as entidades estatais é desnecessária a celebração de convênio para o financiamento de suas atividades básicas - uma vez que a União, os Estados, o DF e os Municípios são o próprio SUS, e a forma desse financiamento já está prevista na LOS - a Constituição e a Lei Orgânica da Saúde só exigem convênio ou contrato entre o Poder Público e a iniciativa privada para complementar a cobertura assistencial, mediante a aquisição de serviços e sua correspondente remuneração. ${ }^{(25)}$

Vale ressaltar a importância da arrecadação financeira feita pelos entes públicos, tendo em vista ser ela a fonte de custeio para as despesas com a prestação de serviços de suas responsabilidades e o repasse de verbas entre si. É o que possibilita sustentação orçamentária às políticas sociais que devem ser materializadas em benefício da população, principalmente, aquelas voltadas ao fortalecimento e agilidade dos serviços que são de competência do Sistema de Saúde.

Compete à Receita Federal, órgão encarregado de fiscalizar as declarações e o recolhimento dos tributos e impostos dos contribuintes obrigatórios no setor privado, averiguar que as grandes empresas e até mesmo os contribuintes individuais cumpram com seu dever de recolher a contribuição de maneira exata, para que o Estado encontre subsistência financeira e concretize à população os direitos sociais. Certamente, tais conquistas são indispensáveis para o respeito e Dignidade da Pessoa Humana.

Lembrando que, quando as suas disponibilidades forem insuficientes para assegurar a garantia assistencial à população de uma determinada região, o SUS pode também se socorrer dos serviços oferecidos pelas empresas privadas que atuam nessa área, mediante contrato ou convênio, realizados com a observância das normas de direito público. Nesse caso, terão preferência as entidades filantrópicas e as sem fins lucrativos.

(24) SCHWARTZ, Germano André Doederlein. op. cit., p. 106.

(25) CARVALHO, Guido Ivan de; SANTOS, Lenir. Comentários à lei orgânica da saúde (leis 8.080/90 e 8.142/90): sistema único de saúde. 2. ed. atual. ampl. São Paulo: Hucitec, 1995. p. 237. 
Os serviços contratados devem submeter-se às normas técnicas e administrativas e aos princípios e diretrizes do Sistema Único. A direção nacional do SUS, lembrando que os Estados que optaram pela municipalização desse Sistema é a direção municipal, deverá fundamentar a forma de pagamento e o valor a ser gasto pelos serviços privatizados em demonstrativo econômico-financeiro. Por tratar-se de uma participação complementar, como afirma o Texto Constitucional e o Capítulo II da Lei n. 8.080/1990, não há obrigatoriedade de as empresas privadas aderirem a essa cooperação. ${ }^{(26)}$

\section{CONSIDERAÇÕES FINAIS}

Procurou-se demonstrar, na redação deste trabalho, que a saúde é um bem de valor indispensável para uma digna existência do ser humano. Isso é pacífico em qualquer ramo do conhecimento que tenha por objetivo estudar os efeitos nocivos que causa ao organismo da pessoa, quando não se faz presente.

Em vista do seu caráter indispensável à sobrevivência da espécie humana, a saúde passou a ser tema de ordem internacional, a ponto de ser elaborada a Constituição da Organização Mundial da Saúde, de 26 de julho de 1946.

No ordenamento jurídico pátrio, a importância do direito à saúde também fora reconhecida pelo Legislador Constituinte de 1988, o qual estabeleceu, de forma explícita, que a saúde é um direito e uma garantia fundamental do indivíduo, merecendo prerrogativas na sua forma de aplicação.

Em razão disso, dispôs no texto da atual Constituição Federal, que competem aos Estados e aos Municípios, os quais possuem autonomia para legislar e executar suas próprias leis em face da descentralização políticoadministrativa, promover políticas públicas que visem a atender as necessidades da população.

Procurou-se evidenciar que nem todas as Constituições Estaduais tratam da proteção legislativa do dependente de drogas ilícitas, embora isso não exonere a obrigação do ente público em proporcionar a sua internação em estabelecimento adequado à sua recuperação, desde que seja observada a lista de espera já existente no local, para que a mesma não seja burlada. Pois neste caso, ocorrerá transgressão aos princípios da universalidade e da igualdade, os quais regem o Sistema Único de Saúde.

(26) Conforme prescrevem os artigos: 24, caput, parágrafo único, 25, 26 e seus parágrafos do Capítulo II da Lei do SUS, e 199 caput, parágrafo primeiro da Constituição Federal de 1988. 
Os Municípios passaram a ter papel central na promoção de ações e serviços que objetivem a recuperação do toxicômano. Para isso, podem contar com a ajuda financeira dos demais entes federativos. Essencial, é que o órgão detentor do Poder Local tenha rígido controle dos recursos que são destinados à Secretaria da Saúde, a fim de que sejam aplicados em benefício dos toxicômanos. Coibir qualquer forma inadequada do uso das verbas públicas, pedindo auxílio ao Ministério Público Estadual em casos que se fizerem necessários.

Não obstante, mudanças com relação à forma de atendimento pelo SUS devem ocorrer, visando à celeridade e à eficiência de um instituto criado com o intuito de proporcionar dignidade ao indivíduo no momento em que se encontrar enfermo. Com relação ao tema proposto, o primeiro passo seria a contratação de agentes especializados na área da medicina para visitar as famílias residentes nas cidades e em seu interior, procurando saber se existe algum membro do grupo familiar usuário de certo tipo de droga. Caso haja, explicar as conseqüências nocivas à sua saúde física e psíquica, provocadas pela substância, apresentandoIhe, ao mesmo tempo, instruções de como deve prosseguir para não fazer mais uso dela. Se necessário, já desenvolver acompanhamento do quadro da doença para não deixá-la chegar à fase da dependência.

O segundo passo seria destinar, no próprio orçamento do ente-público, por meio de lei, uma porcentagem destinada a atender o custo do tratamento de internação do toxicômano em estabelecimento adequado, incluindo o custo da medicação e o acompanhamento de profissionais na área da psiquiatria durante a internação, e por um período após sua saída do estabelecimento.

O terceiro seria os agentes que ocupam a administração instituírem políticas voltadas a desestimular a participação no comércio do tráfico de drogas por meio de programas que incentivem a prática de esportes, o desenvolvimento da cultura artística, a criação de cursos profissionalizantes de forma gratuita. Para isso, podem contar com o um poderoso instrumento: a educação.

Talvez, as alternativas acima apresentadas pareçam difíceis de serem postas em prática. Porém, não impossível, quando se preza pela satisfação dos interesses que objetivem atender às necessidades da coletividade e se reprimam os atos que objetivam atender aos interesses particulares.

\section{REFERÊNCIAS BIBLIOGRÁFICAS}

ÀVILA, Humberto. Teoria dos princípios da definição à aplicação dos princípios jurídicos. 4. ed. São Paulo: Malheiros Ed., 2005.

BRASIL. Constituição (1988). Constituição Federal da República. São Paulo: Saraiva, 2006.

Constituição (1989). Constituição do Estado do Rio Grande do Sul. Disponível em: <http:// www.planalto.gov.br/>. Acesso em: 05 jun. 2006. 
. Constituição (1989). Constituição do Estado de São Paulo. Disponível em: <http://www.planalto.gov.br/>. Acesso em: 05 jun. 2006.

. Constituição (1989). Constituição do Estado de Sergipe. Disponível em: <http://www.planalto.gov.br/>. Acesso em: 05 jun. 2006.

BOBBIO, Norberto. A era dos direitos. Tradução de Carlos Nelson Coutinho. Rio de Janeiro: Campus, 1992.

CARVALHO, Guido Ivan de; SANTOS, Lenir. Comentários à lei orgânica da saúde (leis 8.080/90 e 8.142/90): sistema único de saúde. 2. ed. atual. ampl. São Paulo: Hucitec, 1995.

CURY, leda Tatiana. Direito fundamental a saúde: evolução normatização e efetividade. Rio de Janeiro: Lumem Júris, 2005.

DALLARI, Sueli Gandolfi. Os Estados brasileiros e o direito à saúde. São Paulo: Hucitec, 1995.

MENDES, Eugênio Vilaça et. al. Distritos sanitários: conceitos-chave. In: (Org.). Distrito Sanitário: o processo social de mudança das práticas sanitárias do sistema único de saúde. 4. ed. São Paulo - Rio de Janeiro: Hucitec - Abrasco, 1999.

MENDES, Gilmar Ferreira. Os direitos fundamentais e seus múltiplos significados na ordem constitucional. Revista Brasileira de Direito Público RBDP, Belo Horizonte, ano 1, n. 3, p. 91-103, out./dez. 2003.

SANT'ANNA, Emílio. Demora para obter consulta e tratamento, mesmo em caos delicados, pode chegar a um ano ou mais. O Estado de S.Paulo, São Paulo, 03 dez. 2006. Disponível em: <http://www.idec.og.br/noticia.asp?id=7509>. Acesso: em 16 mar. 2007.

SARLET, Ingo Wolfgang. Algumas considerações em torno do conteúdo, eficácia e efetividade do direito à saúde na Constituição de 1988. Interesse Público, n. 12, p. 91-107. out./dez. 2001.

Dignidade da pessoa humana e direitos fundamentais na Constituição Federal de 1988. Porto Alegre: Livr. do Advogado, 2001.

SCHWARTZ, Germano André Doederlein. Direito à saúde: efetivação em uma perspectiva sistêmica. Porto Alegre: Livr. do Advogado, 2001.

SEITENFUS, Ricardo (Org.). Legislação internacional. São Paulo: Manole, 2004.

SILVA, José Afonso da. Aplicabilidade das normas constitucionais. 3. ed. rev. ampl. e atual. São Paulo: Malheiros Ed., 1999.

VELO, Joe Tennyson. Uso de substâncias psicoativas: aspectos criminológicos e políticos. Revista Brasileira de Ciências Criminais, n. 18, p. 109-122, abr./jun. 1997.

WEICHERT, Marion Alberto. Saúde e federação na Constituição Brasileira. Rio de Janeiro: Lumen Juris, 2004. 